\title{
Family Factors Associated with Hands-On Play and Screen Time During the COVID-19 Pandemic
}

\author{
Shaelyn Stienwandt ${ }^{1}$ (D) Emily E. Cameron ${ }^{1} \cdot$ Melanie Soderstrom ${ }^{1} \cdot$ Mercedes Casar $^{1}$. \\ Cindy Le ${ }^{1} \cdot$ Leslie E. Roos ${ }^{1,2,3}$
}

Accepted: 24 November 2021 / Published online: 6 January 2022

(c) The Author(s), under exclusive licence to Springer Science+Business Media, LLC, part of Springer Nature 2021

\begin{abstract}
Background Parent-child interactions are crucial for child development. The COVID-19 pandemic has negatively affected mental health and increased parenting challenges impacting parent-child functioning.

Objective This study examined parent factors related to more and less enriching child activities during the pandemic through Bronfenbrenner's Ecological Systems framework.

Methods A convenience sample of parents $(N=708)$, primarily mothers $(n=610 ; 87.4 \%)$ aged 35.59 years old $(S D=5.59$; range $=21-72)$, with children ages $2-8$ years completed an online questionnaire between April 14-June 1, 2020. Participants mostly resided in Canada, had an income of $>\$ 100,000$, and identified as White $(82.4 \%)$. Parent-child activities were measured as total weekly time and combined time across activities within two categories: hands-on play and screen time. Bivariate correlations informed blockwise linear regression models.

Results For families with childcare needs, parental anxiety was associated with higher total hands-on play, combined hands-on play, and combined screen time. Families without childcare needs indicated parenting stress was associated with lower total hands-on play and combined hands-on play, and higher supervised screen time. Family structure and indices of socioeconomic status were also predictive of activities across childcare needs and child ages.

Conclusions To promote high-quality parent-child interactions and positive developmental outcomes during the pandemic, childcare needs and parent wellbeing should be supported, while evidence-based guidelines for child screen time should be further researched in this context.
\end{abstract}

Keywords Screen time $\cdot$ Hands-on play $\cdot$ Parent-child interactions $\cdot$ COVID-19 $\cdot$ Parenting

Shaelyn Stienwandt

stienwas@myumanitoba.ca

1 Department of Psychology, University of Manitoba, 190 Dysart Road, Winnipeg,

Manitoba R3T 2N2, Canada

2 Department of Pediatrics and Child Health, University of Manitoba, Winnipeg, Canada

3 Children's Hospital Research Institute of Manitoba, Winnipeg, Canada 


\section{Introduction}

Parents play an essential role in child development. Supportive and enriching learning environments are crucial for promoting positive cognitive and social-emotional development in children (Ginsburg, 2007). Families are facing unprecedented demands on parent-child interactions in the context of the novel coronavirus disease (COVID-19), due to the closure of schools/daycares and large shifts in remote work for parents (Cluver et al., 2020; Statistics Canada Labour Force Survey, 2020). Further, the COVID-19 pandemic has had detrimental effects on parental mental health and parenting stress, which can lead to more negative parenting strategies and behaviours and affect child development if left unaddressed (Cameron et al., 2020; Goodman et al., 2011; Roos et al., 2021; Sweeney \& MacBeth, 2016). As such, while the pandemic has provided a potential opportunity for more developmentally enriching parent-child interactions in some situations with more time at home with family, it has also increased potential exposure to less supportive interactions in the context of parental mental health concerns or family stressors. Thus, examining the frequency and nature of parent-child activities in relation to parent factors (e.g., mental health) and unmet needs (e.g., childcare) during the pandemic is a key step in understanding how best to support parents in nurturing their child's development.

\section{Theoretical Underpinnings}

Bronfenbrenner's theory of ecological development is a helpful lens for understanding the evolving changes in families and their activities during the pandemic. The theory postulates five distinct levels of environmental influence on child development-microsystem, mesosystem, exosystem, macrosystem, and chronosystem (Bronfenbrenner, 1986; Rosa \& Tudge, 2013). The microsystem is defined as the most proximal setting in which a child develops including the home, childcare setting, and people with whom the child has faceto-face interactions. The second level, the mesosystem, includes the interactions between multiple microsystems (e.g., teachers' communication with parents, such as sending home schoolwork during the early pandemic shutdowns). The exosystem then focuses on the indirect environment that influences child functioning and development (e.g., characteristics of a parent's workplace that influence the parent's availability to spend time with the child). Next, the macrosystem includes the social structures and events encompassing a child's environment (e.g., COVID-19 public health recommendations and social policies). Finally, the chronosystem level includes broader factors that change or remain the same over time (e.g., historical events such as the COVID-19 pandemic or parental divorce).

Within the COVID-19 pandemic, child development has been impacted across each level of Bronfenbrenner's model, leaving young children particularly vulnerable to the influences of COVID-19-related changes. The pandemic has substantially changed the chronosystem, while the public health recommendations and cultural values associated with the pandemic reflect changes to the macrosystem. Further, at the level of the exosystem, changes to parent workplaces and family dynamics may have created additional family changes. Children's mesosystems have been altered through changes to school life and home routines. Across these levels, shifts may produce developmental stressors, such as social isolation and uncertainty (Loades et al., 2020). However, strong parent-child relationships within the microsystem and developmentally enriching activities have been shown to protect against stressors (McDonald et al., 2016). These interactions may also 
have the potential to protect against pandemic-specific stressors too. As such, a first step to determining the impact of the pandemic on family functioning is to examine variability in different family activities.

\section{The Role of the Parent-Child Relationship}

Parents are a key part of a child's microsystem and influence emotion regulation, executive functioning, language development and social functioning (Barnett et al., 2012; Fay-Stammbach, et al., 2014; Morris et al., 2007; Rowe, 2012). 'Serve and return' parenting, where children initiate interest in an activity and parents respond appropriately, is enriching because it supports children's learning and social skills development (Shonkoff et al., 2016). Opportunities for such high-quality interactions are readily available during hands-on play, such as crafts, building blocks, and imaginary role-play activities (Gardner, 1994). Hands-on play predicts children's later conduct behaviours, emotion regulation, understanding, and creativity (Gardner, et al. 2003; Linsey \& Colwell, 2003; Hoffmann \& Russ, 2012). Children's engagement in positive hands-on play is linked to maternal demonstration of play, initiation of play, knowledge of child development, and parental playfulness (Cote \& Bornstein, 2009; McMillin et al., 2015; Menashe-Grinberg \& Atzaba-Poria, 2017). However, parental mental health challenges, higher parenting stress, greater financial strain and lower education are associated with lower quality interactions (Field, 2018; Goodman et al., 2011; Shaffer \& Obradović, 2017; Van Gampelaere et al., 2020).

Screen time, which would not be considered a 'serve and return' interaction, is another family activity that has changed during the pandemic, partially due to increased reliance on virtual technology for schooling and interacting with friends and family (Eyimaya \& Irmak, 2021). While screen time can include opportunities for prosocial or educational virtual experiences, there are also concerns regarding the amount and quality of screen time children are exposed to as a function of increased time at home (Shin \& Al-Habaibeh, 2020). Before the pandemic, more than two-thirds of children were not meeting national screen time recommendations (i.e., no media for children under two years and one hour of media per day for children over two years; American Academy of Pediatrics, 2018; Atkin et al., 2014). Research has shown that greater screen use in childhood is associated with family factors such as parents' own screen time, parental attitude about child media use, and maternal depression (Duch et al, 2013; Lauricella et al., 2015). For children, excessive screen time has been associated with lower language skills, lower school readiness, less classroom engagement, social-emotional challenges, and reduced psychological wellbeing (Domingues-Montanari, 2017; Madigan et al., 2020; Pagani et al., 2013; Poulain et al., 2018). The possible detrimental effects of screen use may be a result of the reduction of parent-child interactions in favour of independent screen use and overall lower family functioning (Radesky \& Christakis, 2016). However, emerging literature indicates that some technology use may be a positive use of screens, such as educational apps and videoconferencing to socialize or engage in activities like virtual storybook readings (Gaudreau et al., 2020; McClure \& Barr, 2017; Neumann, 2018). Similarly, child screen time may provide a relatively safe activity for children to engage in, allowing parents to complete their responsibilities or facilitate challenging parenting tasks such as mealtime (Elias \& Sulkin, 2019). Yet, despite the wide acknowledgement that children are spending more time on screens during the pandemic, both for educational and non-educational purposes, little research exists to evaluate the family factors associated with children's screen use. 
Identifying these factors may help to inform future research to support at-risk families to engage in developmentally enriching activities to promote child development.

\section{Obstacles to Positive Parent-Child Interactions}

Despite the documented importance of positive parent-child interactions, parents may face obstacles when initiating interactions with their children. During the COVID-19 pandemic, changes to children's mesosystems (e.g., relationships between school, daycare, neighbourhood etc.) and exosystems (e.g., parents' work and relationships) may increase parental stress (Bronfenbrenner, 1986). Emerging research since the onset of the pandemic has shown that parents are reporting high levels of stress (Brown et al., 2020) and mental health concerns (Cameron et al., 2020). This is concerning given the pre-pandemic link between maternal psychosocial distress and children's later externalizing and internalizing behaviours (Dubois-Comtois et al., 2013). Further, lower quality parenting during the pandemic has been associated with several household and pandemic risk factors (Roos et al., 2021). Importantly, caregiver depression during the pandemic has been associated with parent-child relationship disruptions (Roos et al., 2021), consistent with pre-pandemic research reporting that the adverse impact on parent-child interactions leads to an increased risk of negative child outcomes (Field, 2018; Goodman et al., 2011).

An additional obstacle faced by parents is challenging child behaviours, especially in the context of the pandemic. For instance, there is a strong relationship between parent mental health concerns and children's internalizing and externalizing behaviours, which often results in subsequent increases in parenting challenges (Priel et al., 2019; Sweeney \& MacBeth, 2016). Research has shown that children who demonstrate more challenging behaviour are more likely to receive increased screen time, indicating that screen time may represent a necessary strategy for modulating parenting stress and capacity (Radesky et al., 2014). Given that the COVID-19 pandemic has increased parenting stress and mental health challenges (Cameron et al., 2020), screen time may be a strategy more heavily relied on by parents. Parent-child play activities may also be negatively impacted during the pandemic (e.g., less frequent or lesser quality) due to increased mental health challenges experienced by parents (Edhborg et al., 2003; Wilson \& Durbin, 2010).

An additional consideration is families' economic and childcare needs during the pandemic. Before the pandemic, almost one-third of Canadian families and one-half of American families reported living in a 'childcare desert', referring to a neighbourhood where there is only one childcare spot for every three children (MacDonald, 2018; Malik \& Hamm, 2017). With school and daycare closures due to COVID-19, we expect that many more families are experiencing unmet childcare needs, potentially impacting the quality and quantity of parent-child interactions. Further, the economic impacts of the pandemic may add an additional obstacle for families engaging in developmentally supportive activities. Research has documented that parents reporting lower socioeconomic status (SES) may display less supportive parenting behaviours (Hoffman, 2003). Further, acute declines in income lead to greater family conflict and parental hostility (Conger et al., 1994). Yet, as parents manage their roles as members of the workforce, providers, and caregivers in an uncertain time, the impact of the COVID-19 pandemic on family activities is unknown. 


\section{The Present Study}

Daycare and school closures combined with work-from-home policies for many parents have produced immense changes across children's ecological systems. Yet, there has been no research to date examining the changes to parent-child interactions as a result of the pandemic. Thus, the primary aim of the current study was to examine how household factors (e.g., sociodemographics, parent depression/anxiety, parenting stress) and COVID19-related changes increased or decreased odds of engaging in developmentally supportive dyadic activities (i.e., hands-on play) and less supportive activities (i.e., non-educational screen time) between parents and children. Met and unmet childcare needs during the pandemic represent a crucial factor in the consideration of changes to parent-child interactions. As such, we investigated the primary aim stratified across childcare met or unmet needs. We hypothesized that (1) higher parental stress, anxiety, depression, and past parental mental health challenges would predict less time spent on hands-on play activities and greater time spent on screen time activities, (2) greater financial strain, food insecurity, and employment loss due to COVID-19 would predict less time spent on hands-on play and greater time spent on screen time, and (3) being in a higher-risk sociodemographic category (e.g., lower SES, single-parent household) would predict less time spent on hands-on play and greater time spent on screen time. The goal of this research is to inform program development aimed at reducing parental barriers to engagement in developmentally supportive activities during the current pandemic and beyond.

\section{Method}

\section{Recruitment}

Participants were recruited between April 14, 2020, and June 1, 2020, as an online convenience sample through online advertisements, social media postings, and indirect recruitment through media interviews discussing the pandemic. Participants were included if they were 18 years or older, parenting at least one child aged 2-8 years, and had access to technology to complete the online survey. As the researchers are based out of the University of Manitoba, recruitment strategies were centred around networking within the city of Winnipeg; however, there were no exclusion criteria based on participant location. Due to the nature of the pandemic, COVID-19-related restrictions (e.g., limit on public gatherings, the closing of non-essential services, self-isolation policies) were differentially more drastic at the start of recruitment. Procedures to restore services began in the latter month of recruitment.

\section{Procedure}

REDCap electronic data capture tool hosted at the University of Manitoba was used to obtain informed consent before participants completed the survey (Harris et al., 2009). Participants were entered in a draw for a chance to win one of five $\$ 100$ CAD electronic gift certificates. This study was approved by the university research ethics review board. The original data is available from the authors upon request. 


\section{Measures}

\section{Sociodemographic and COVID-19-Related Information}

Family demographic information, including any changes as a result of the COVID-19 pandemic, was obtained from parents. This information included parent income, education, marital status, household factors, and employment status. Additional indices of socioeconomic functioning included current financial strain and food insecurity, which were dichotomized into presence or absence. Biological mothers/fathers, adoptive parents, foster parents, and any other individual identifying as the primary caregiver of the child were included in the study. For this reason, parents were also asked to identify their relationship with each of their children through an open-ended response. Parents indicated whether they had current unmet childcare needs during the COVID-19 pandemic. Parents expressing unmet childcare needs either had no childcare and needed it, had some childcare but needed more, or had non-ideal childcare (e.g., provided by elderly grandparents). Parents without childcare needs expressed having sufficient care. This variable was used to differentiate two cohorts of parents during the analyses (see Statistical Analysis).

\section{Mental Health}

A self-report Adult Mental Health Disorder Checklist (AMHDC) was utilized to obtain information from parents about their current or historical mental health diagnoses and treatment. This method of assessing mental health is consistent with previous research making use of self-report mental health history (Sanchez-Villegas et al., 2008). Mental health diagnoses in children were assessed through parent-report on the Child Mental Health Disorder Checklist (CMHDC). This author-compiled measure was developed to identify any diagnosed mental health disorders for children participating in the current study. The current study requests that caregivers note any previously diagnosed mental health disorders (e.g., Autism Spectrum Disorder, Down Syndrome, Attention-Deficit Hyperactive Disorder, etc.) for their child to participate.

\section{The Center for Epidemiologic Studies Depression (CESD) and Revised (CESD-R)}

Parents with children in the age range of 2-8 years old completed either the 20 -item CESD $(n=209)$ or the CESD-R $(n=499)$ to measure the frequency of depressive symptoms that they experienced within the past week (Eaton et al., 2004; Radloff, 1977). The CESD was used in the first 351 surveys (in the larger study), while the rest of the surveys used the CESD-R. Both scales were measured through the original CESD Likert scale and its summative score ranges. Therefore, the scales will now be referred to as CESD. Although the results of the self-report survey are not equivalent to a clinical diagnosis, a clinical cut-off score of $\geq 16$ was utilized as an optimal specificity cut-off to identify depressive cases (Eaton et al., 2004; Radloff, 1977). Good to excellent internal consistency was found in the current study (CESD: $\alpha=0.88$; CESD-R: $\alpha=0.94$ ). 


\section{Generalized Anxiety Disorder 7-Item Scale (GAD-7)}

Parents with children 2-8 years old took part in the seven-item GAD-7 (Spitzer et al., 2006). This measure was used to measure symptoms of parental anxiety experienced by these parents. To identify general anxiety, a clinical cut-off score of $\geq 10$ on the GAD-7 was used (Spitzer et al., 2006). Excellent internal consistency in the current study was found $(\alpha=0.92)$.

\section{Parenting Stress Index (PSI)}

The PSI was used to assess how demographic characteristics along with both child and parent characteristics contribute to stressful parent-child interactions (Abidin, 2012). Subscales used for children include hyperactivity, demandingness, and adaptability whereas the subscales used for parents include measures of competence, attachment, and health. This measure has often been used as a screening tool to identify issues that may lead to problematic behaviour for the child and/or parent. Internal consistency was excellent in the current study $(\alpha=0.94)$.

\section{Family Activities During COVID-19}

Author-compiled measures were developed to evaluate the kinds of activities families are enjoying while staying at home during the COVID-19 pandemic. Activities were measured across two categories: hands-on play and screen time. Hands-on activities included dance or music activities, making meals or snacks together, arts and crafts, and playing with toys together. Combined screen time activities included watching television or movies together, connecting with family or friends over the phone or video chat, and playing games on a tablet/phone/computer. Educational activities were not included in screen time variables. Time spent in these activities was further measured in two ways: through a single question regarding time investment (e.g., "How many hours per week are you typically spending doing hands-on play with your children?) and through estimated time in the aforementioned activities. Notably, the single-item assessing screen time measured parent-supervised child screen time (i.e., "How many hours per week are you typically spending doing supervision while your children engage in screen time?"), which was used to measure independent child screen activities. Reported time for relevant activities was then summarized into a single value indicating hours per week. For hands-on play, the single-question assessment will be referred to as "total" time spent in each activity category, while the summarized score will be referred to as "combined" time. For screen time, the single-question assessment will be referred to as "supervised" screen time, while the summarized score will be referred to as "combined" screen time.

\section{Statistical Analysis}

Analyses were conducted using IBM SPSS Statistics Version 25. Dependent variables were analyzed using Little's Missing Completely at Random (MCAR) test to determine the nature of missing data. The test indicated that data was missing at random $\left(\chi^{2}=33.37, p=0.640\right)$, meaning all available data was used in the analyses without required imputation. Analyses were conducted separately for parents with a child in 
the 2-4 year and 5-8 year categories. To minimize data loss for each age group, parents were included in each category if they had multiple children meeting age criteria. Descriptive statistics were conducted to describe the sample characteristics. Bivariate correlations were then conducted separately based on (1) child age group and (2) childcare needs. Parents indicated whether they had met or unmet childcare needs; due to the nature of the research question, this variable was used to conduct separate analyses. Significant bivariate correlations across the six outcomes measures were then evaluated using blockwise linear regression. Non-modifiable factors (e.g., income, education, age) were entered into the first block; any variables not significant over and above the contributions of other variables in the model were removed prior to analyzing the second block. Block 2 consisted of all modifiable factors (e.g., depression, anxiety, stress) that demonstrated a significant correlation with the outcome measure.

\section{Results}

\section{Participant Characteristics}

Participants $(N=708)$ consisted primarily of mothers $(n=610 ; 87.4 \%)$ with a smaller portion of father respondents $(n=70 ; 10.0 \%)$. A small subset of participants simply indicated "parent" $(n=15 ; 2.1 \%)$ or another type of primary caregiver $(n=3 ; 0.4 \%)$, while $n=10$ participants did not respond. Most participants identified as being White (82.4\%), while a small number identified as being from a racial or ethnic minority group $(17.6 \%)$. Average parental age was 35.59 years old $(S D=5.59$; range $=21-72)$. Households consisted of $2.03(S D=0.44)$ adults and $1.97(S D=0.82)$ children on average, and a small portion $(5.0 \%)$ of parents indicated they were from a single-adult household. As the majority of parents reported multiple children in the household, parents were classified based on child age categories: at least one child aged 2 to $<5$ years $(n=465)$ and 5 to $<8$ years old $(n=386)$. Parents with multiple children could be included in both categories due to analyses being conducted separately for each child age group. Participants were primarily married or common-law $(91.4 \%)$, had at least a bachelor's degree $(57.4 \%)$, reported on average an annual household income of $>\$ 100,000$, and were residing in Canada (84.9\%), the United States (11.2\%) or international countries (4.0\%). This sample, therefore, represents a relatively high SES, White, Western population. Within the context of the COVID-19 pandemic, $44.3 \%$ of parents indicated that they had unmet childcare needs. While most participants $(99.7 \%)$ had not experienced a diagnosis of COVID-19, $22.5 \%$ indicated that they knew someone personally who had been diagnosed. Of these individuals, $27.0 \%$ were hospitalized and $63.5 \%$ had recovered at the time of survey completion (Table 1).

\section{Impact of COVID-19 on Children's Exosystems}

In terms of employment, $15.7 \%$ of parents reported that they or someone in the household had been laid off due to the COVID-19 pandemic. One in ten $(10.1 \%)$ parents reported that they or someone in their household had lost at least half of their regular work hours during the pandemic. Financial strain was reported by over one-third of parents (37.9\%). 
Table 1 Characteristics of the Sample

\begin{tabular}{lll}
\hline Characteristic & $\%$ & Valid N
\end{tabular}

Parent Education Level

Some high school

High school diploma or equivalent

0.9

6

College/Technical School

8.0

Bachelor's degree

Above bachelor's degree

Partner Education Level

Some high school

High school diploma or equivalent

College/Technical School

Bachelor's degree

30.4

Above bachelor's degree

27.0

Household Employment Status during COVID-19

Hours consistent

More than half of regular hours

10.4

Laid off

10.1

Salaried

Total Annual Household Income

$\leq \$ 20,000$

$\$ 20,001-\$ 40,000$

$\$ 40,001-\$ 60,000$

$\$ 60,001-\$ 80,000$

$\$ 80,001-\$ 100,000$

$>\$ 100,000$

Marital Status

Married/Common Law

Divorced/Separated

Single (never married)

3.6

Number of children

0

Previous Maternal Mental Health Diagnosis/Treatment

Apply for Federal Insurance Benefits

Extremely likely

Neutral

Unlikely

Extremely unlikely

Parent in a Vulnerable Population

Underlying medical condition

Compromised immune system 
Table 1 (continued)

\begin{tabular}{lcc}
\hline Characteristic & $\%$ & Valid N \\
\hline Partner in a Vulnerable Population & & \\
Underlying medical condition & 6.4 & 45 \\
Compromised immune system & 2.0 & 14 \\
Child in a Vulnerable Population & & 52 \\
Underlying medical condition & 7.4 & 19 \\
Compromised immune system & 2.7 & 290 \\
Medical Services Impacted by COVID-19 & 41.5 & 86 \\
Racial/Ethnic Minority Background & 17.6 &
\end{tabular}

\section{Parent-Child Activities}

Direct microsystem activities were measured in the total sample. Parents reported an average of $M=29.07$ ( $S D=18.44$ ) hours was spent on hands-on play per week; time across combined hands-on play (e.g., arts and crafts, playing with toys, making meals or snacks, engaging in music or dance) was $M=19.56(S D=15.91)$ hours per week. Total time spent supervising child screen activities was estimated at $M=16.48(S D=11.06)$ hours per week; combined screen time based on a specific activity (e.g., playing games on tablet/phone/computer, phone or video chat, watching TV or movies) was $M=17.34$ $(S D=14.22)$ hours per week. Time spent engaging in each category is described in Table 2 by child age group and childcare needs.

Table 2 Descriptive Statistics for Hands-on Play and Screen Time Activities by Child Age Group

\begin{tabular}{|c|c|c|c|c|c|c|}
\hline \multirow[t]{2}{*}{ Outcome variable } & \multicolumn{3}{|c|}{2 to 4 years } & \multicolumn{3}{|c|}{5 to 8 years } \\
\hline & M & $\mathrm{SD}$ & Range & M & SD & Range \\
\hline Total hands-on play & 31.33 & 18.66 & $0.00-105.00$ & 25.23 & 17.20 & $0.00-105.00$ \\
\hline Unmet childcare needs & 32.48 & 19.48 & $0.00-105.00$ & 26.78 & 18.31 & $0.00-105.00$ \\
\hline No needs & 30.69 & 18.10 & $0.00-84.00$ & 23.79 & 16.01 & $0.00-84.00$ \\
\hline Combined hands-on play & 21.05 & 17.18 & $0.50-131.00$ & 17.04 & 13.82 & $0.00-77.00$ \\
\hline Unmet childcare needs & 19.87 & 15.54 & $1.00-77.00$ & 16.58 & 15.11 & $0.00-77.00$ \\
\hline No needs & 22.24 & 18.58 & $0.05-131.00$ & 17.43 & 12.92 & $0.50-59.50$ \\
\hline Supervised screen time & 15.42 & 9.80 & $0.00-70.00$ & 17.53 & 11.73 & $0.00-84.00$ \\
\hline Unmet childcare needs & 16.08 & 9.74 & $0.00-56.00$ & 18.98 & 11.90 & $0.00-56.00$ \\
\hline No needs & 14.96 & 10.00 & $0.00-70.00$ & 16.09 & 11.25 & $0.00-84.00$ \\
\hline Combined screen time & 17.45 & 14.53 & $0.00-97.00$ & 16.83 & 15.01 & $0.00-97.00$ \\
\hline Unmet childcare needs & 26.52 & 15.72 & $0.50-97.00$ & 17.87 & 17.79 & $0.25-97.00$ \\
\hline No needs & 18.41 & 13.64 & $0.00-76.00$ & 16.35 & 13.07 & $0.00-63.00$ \\
\hline
\end{tabular}




\section{Correlates of Hands-on Play}

Correlations of total hands-on play (i.e., single-question measurement of weekly play in hours) and combined hands-on play (i.e., summed measurement of time spent engaging in specific play activities) were examined to inform blockwise linear regressions.

\section{Parents of Preschool Children with Childcare Needs}

Total hands-on play was negatively correlated with the number of children in the home, greater employment loss, and greater parental anxiety. Combined hands-on play was significantly related to a greater number of children in the home and lower parent education (Table 3). In the blockwise linear regression (Table 6), number of children in the home was negatively associated with total hands-on play $(\beta=-0.18, F(3,142)=5.35$, $p=0.022)$ and positively related to combined hands-on play $(\beta=0.24, F(2,115)=7.02$, $p=0.009)$. Parent education was also inversely associated with combined hands-on play $(\beta=-0.19, F(2,115)=4.51, p=0.036)$, and increased parental anxiety was associated with more time spent engaging in total hands-on play $(\beta=0.30, F(3,142)=14.01$, $p<0.001)$.

\section{Parents of Preschool Children Without Childcare Needs}

Total hands-on play was significantly associated with fewer children in the home, lower parenting stress, higher parental age, and non-female parental status. Combined handson play was negatively related to the number of children in the home and positively associated with parental sex (Table 4). In the linear regression (Table 5), total hands-on play was associated with number of children in the home $(\beta=-0.21, F(3,209)=10.05$, $p=0.002)$, parental age $(\beta=0.22, F(3,209)=11.42, p=0.001)$, and parenting stress $(\beta=-0.18, F(3,209)=7.95, p=0.005)$, while combined hands-on play was significantly associated with parent $\operatorname{sex}(\beta=0.24, F(3,209)=7.45, p=0.007)$, and number of children in the home $(\beta=-0.19, F(3,209)=4.84, p=0.030)$.

\section{Parents of School-Aged Children with Childcare Needs}

Total hands-on play was significantly associated with increased food insecurity and parental anxiety. Combined hands-on play was associated with a greater number of children in the home and increased anxiety (Table 3 ). In the blockwise linear regression (Table 6), combined hands-on play was associated with number of children $(\beta=0.37$, $F(2,85)=13.75, p<0.001)$ and parental anxiety $(\beta=0.26, F(2,85)=6.82, p=0.011)$. There were no significant relationships with total hands-on play when significant bivariate variables were included together (Table 6).

\section{Parents of School-Aged Children Without Childcare Needs}

Total hands-on play was significantly associated with being married. Combined handson play was associated to employment loss, lower parent education, and lower parenting stress (Table 4). In the blockwise linear regression (Table 5), total hands-on paly was associated with marital status $(\beta=0.15, F(1,201)=4.66, p=0.032)$, while combined 


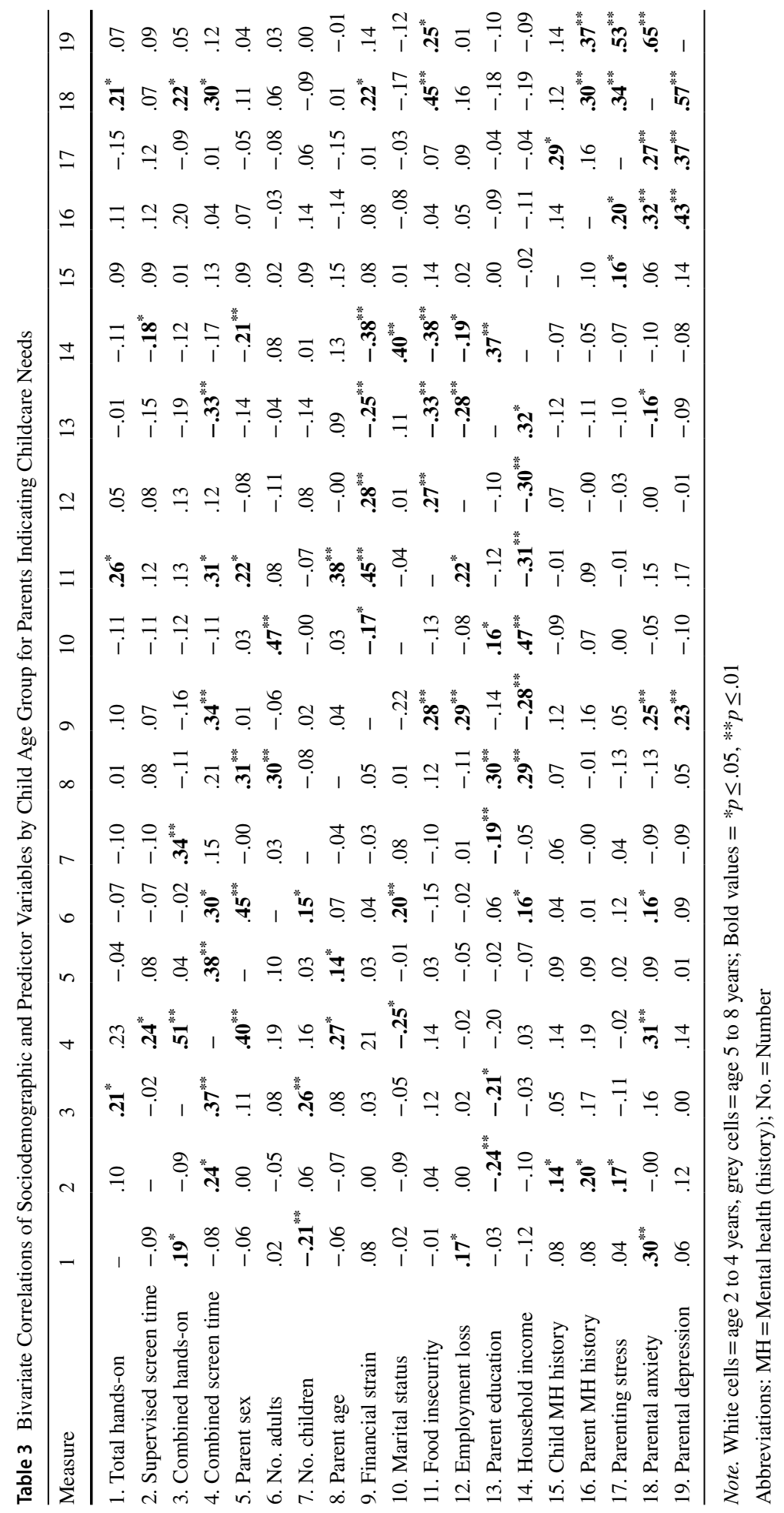




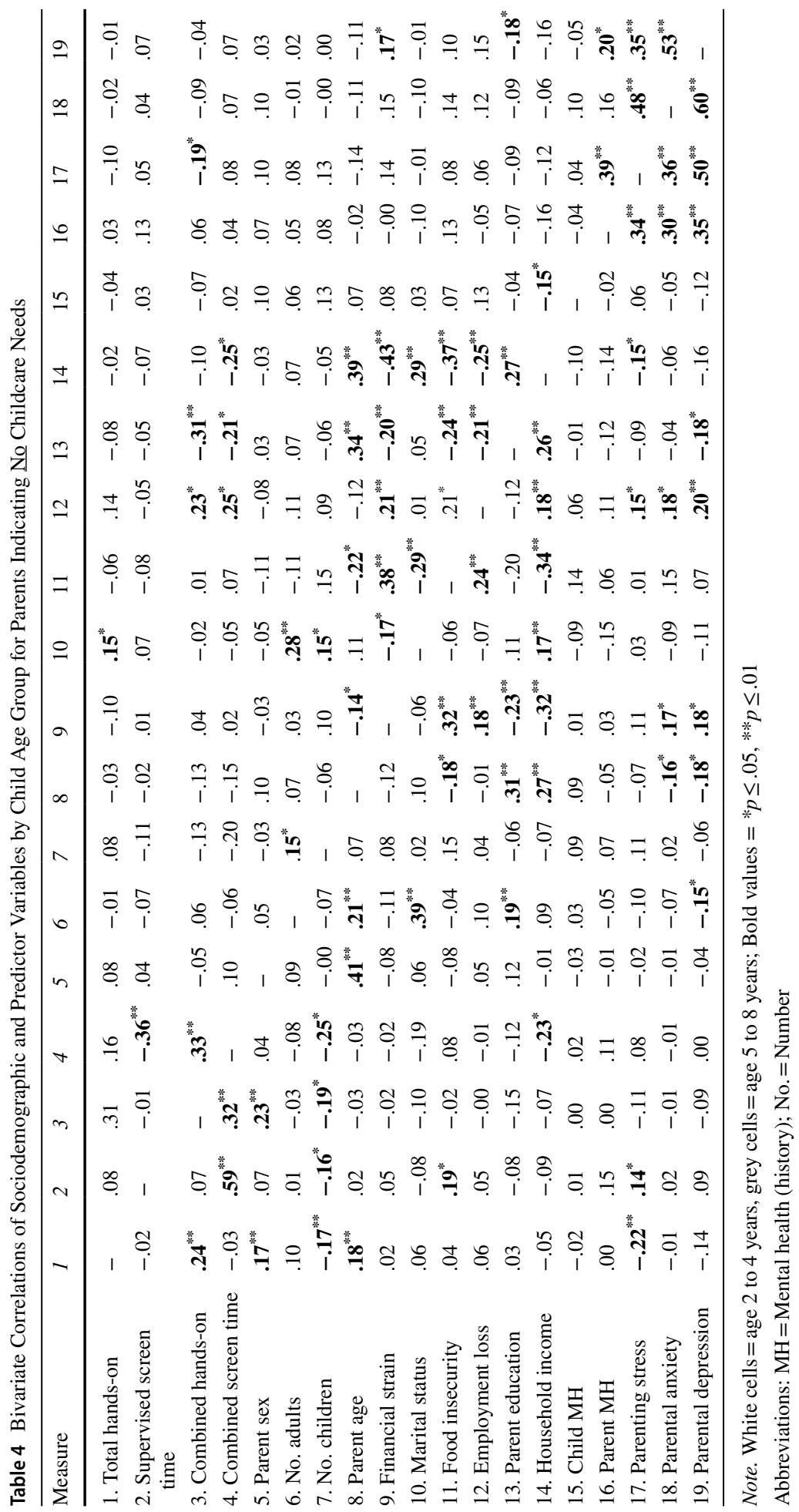


Table 5 Final Linear Regression Models for Families Indicating № Childcare Needs by Child Age

\begin{tabular}{|c|c|c|c|c|c|c|c|c|}
\hline \multirow[t]{2}{*}{ Predictor Variable } & \multicolumn{4}{|c|}{2 to 4 years } & \multicolumn{4}{|c|}{5 to 8 years } \\
\hline & $\beta$ & $S E$ & $t$ & $p$ & $\beta$ & $S E$ & $t$ & $p$ \\
\hline \multicolumn{9}{|l|}{ Total hands-on play } \\
\hline No. of children & -0.21 & 1.57 & -3.17 & .002 & & & & \\
\hline Parental age & 0.22 & 0.21 & 3.38 & .001 & & & & \\
\hline Parenting stress & -0.18 & 0.12 & -2.82 & .005 & & & & \\
\hline Marital status & & & & & 0.15 & 4.40 & 2.16 & .032 \\
\hline \multicolumn{9}{|c|}{ Combined hands-on play } \\
\hline Participant sex & 0.24 & 4.64 & 2.73 & .007 & & & & \\
\hline No. of children & -0.19 & 2.07 & -2.20 & .030 & & & & \\
\hline Parent education & & & & & -0.33 & 0.83 & -3.67 & $<.001$ \\
\hline Parenting stress & & & & & -0.21 & 0.11 & -2.38 & .019 \\
\hline \multicolumn{9}{|c|}{ Supervised screen time } \\
\hline No. of children & -0.19 & 1.10 & -2.31 & .022 & & & & \\
\hline Food insecurity & 0.23 & 3.39 & 2.84 & .005 & & & & \\
\hline Parenting stress & 0.20 & 0.08 & 2.48 & .014 & & & & \\
\hline \multicolumn{9}{|c|}{ Combined screen time } \\
\hline No. of children & -0.33 & 1.70 & -3.42 & .001 & & & & \\
\hline Household income & -0.29 & 0.37 & -3.00 & .003 & -0.18 & 0.40 & -1.64 & .104 \\
\hline Parent education & & & & & -0.10 & 1.04 & -0.90 & .370 \\
\hline Employment loss & & & & & 0.15 & 2.88 & 1.40 & .165 \\
\hline
\end{tabular}

Note Only measures that were significant in the correlation analyses were entered into the model; No. $=$ Number

hands-on play was associated with parent education $(\beta=-0.33, F(2,110)=13.50$, $p<0.001)$ and parenting stress $(\beta=-0.21, F(2,110)=5.67, p=0.019)$.

\section{Correlates of Screen Time}

Correlations of supervised screen time (i.e., single-question measurement of weekly screen time in hours) and combined screen time (i.e., summed measurement of time spent engaging in specific screen time activities) were examined to inform blockwise linear regressions.

\section{Parents of Preschool Children with Childcare Needs}

Supervised screen time was negatively correlated with parent education and positively correlated with child mental health history, parent mental health history, and parenting stress. Combined screen time was positively associated with parental age, anxiety, nonmothers, and negatively related to marital status (Table 3). In the blockwise linear regression (Table 6), supervised screen time was associated with parent education $(\beta=-0.21$, $F(3,133)=6.49, p=0.012)$. Combined screen time was significantly associated to parent sex $(\beta=0.37, F(2,82)=13.37, p<0.001)$ and parental anxiety $(\beta=0.25, F(2,82)=6.25$, $p=0.014)$. 
Table 6 Final Linear Regression for Families Indicating Unmet Childcare Needs by Child Age

\begin{tabular}{|c|c|c|c|c|c|c|c|c|}
\hline \multirow[t]{2}{*}{ Predictor Variable } & \multicolumn{4}{|l|}{2 to 4 years } & \multicolumn{4}{|l|}{5 to 8 years } \\
\hline & $\beta$ & $S E$ & $t$ & $p$ & $\beta$ & $S E$ & $t$ & $p$ \\
\hline \multicolumn{9}{|l|}{ Total hands-on play } \\
\hline No. of children & -0.18 & 1.97 & -2.31 & .022 & & & & \\
\hline Employment loss & 0.11 & 3.34 & 1.43 & .155 & & & & \\
\hline Food insecurity & & & & & 0.20 & 6.45 & 1.71 & .092 \\
\hline Parental anxiety & 0.30 & 3.23 & 3.74 & $<.001$ & 0.15 & 4.66 & 1.30 & .198 \\
\hline \multicolumn{9}{|c|}{ Combined hands-on play } \\
\hline No. of children & 0.24 & 1.83 & 2.65 & .009 & 0.37 & 1.72 & 3.71 & $<.001$ \\
\hline Parent education & -0.19 & 0.93 & -2.12 & .036 & & & & \\
\hline Parental anxiety & & & & & 0.26 & 3.66 & 2.61 & .011 \\
\hline \multicolumn{9}{|c|}{ Supervised screen time } \\
\hline Parent education & -0.21 & 0.55 & -2.55 & .012 & & & & \\
\hline Household income & & & & & -0.18 & 0.24 & -2.28 & .024 \\
\hline Parent MH history & 0.17 & 1.75 & 1.97 & .051 & & & & \\
\hline Parenting stress & 0.06 & 0.10 & 0.72 & .474 & & & & \\
\hline \multicolumn{9}{|c|}{ Combined screen time } \\
\hline Parent sex & 0.37 & 3.51 & 3.66 & $<.001$ & & & & \\
\hline Parental anxiety & 0.25 & 3.44 & 2.50 & .014 & 0.30 & 5.28 & 2.53 & .014 \\
\hline
\end{tabular}

Note. Only measures that were significant in the correlation analyses were entered into the model; $\mathrm{MH}=$ Mental health; No. $=$ Number

\section{Parents of Preschool Children Without Childcare Needs}

Significant correlations for supervised screen time include a negative association with number of children in the home and positive association with food insecurity and parenting stress. Combined screen time was negatively related to the number of children in the home and household income (Table 4). In the blockwise linear regression (Table 5), supervised screen time was associated with number of children in the home $(\beta=-0.19$, $F(3,138)=5.35, p=0.022)$, food insecurity $(\beta=0.23, F(3,138)=8.04, p=0.005)$, and parenting stress $(\beta=0.20, F(3,138)=6.14, p=0.014)$. Combined screen time was similarly related to number of children $(\beta=-0.33 F(2,94)=11.71, p=0.001)$ and household income $(\beta=-0.29, F(2,94)=9.01, p=0.003)$.

\section{Parents of School-Aged Children with Childcare Needs}

Supervised screen time was associated with lower household income. Combined screen time was positively associated with non-mothers, the number of adults in the home, financial strain, food insecurity, parent anxiety, and negatively related to parent education (Table 3). In the blockwise linear regression (Table 6), supervised screen time was associated with household income $(\beta=-0.18, F(1,156)=5.22, p=0.024)$. Combined screen time was associated with parental anxiety $(\beta=0.30, F(1,67)=6.40, p=0.014)$. 


\section{Parents of School-Aged Children Without Childcare Needs}

Supervised screen time was not significantly correlated with any independent variables. Combined screen time was associated with employment loss, lower parental education, and lower household income (Table 4). In the blockwise linear regression (Table 5), there were no significant relationships between bivariate predictors of both supervised and combined screen time.

\section{Discussion}

To our knowledge, this study is the first to describe changes to parent-child interactions during the COVID-19 pandemic. Results provide insight into parent and family factors that may influence these interactions, including parental anxiety, stress, and household factors. Given the importance of childcare considerations when describing children's microsystems, mesosystems, and exosystems, family activities were evaluated across met and unmet childcare needs. Importantly, almost half of the families in the current study reported unmet childcare needs in the context of the pandemic. Notably, while there were some shared factors associated with parent-child interactions across families with and without unmet childcare needs, distinct factors associated with parent-child interactions also emerged.

This study examined two types of child activities through parent-report: hands-on play and screen time. Previous research has demonstrated that parents' self-report on their daily interactions with their child(ren) has ecological validity similar to laboratory task observations (Gardner, 2000). Hands-on play was presumed to be developmentally supportive based on the extant literature defining joint play as an opportunity for dyadic interactions that promote children's prosocial development (Gardner, 1994; Shonkoff et al., 2016). Non-educational screen time was presumed to be less developmentally supportive due to research demonstrating higher screen time's association with reduced parent-child engagement, creative play, more behavioural problems, poorer vocabulary, and delayed achievement of developmental milestones (McArthur et al., 2021; Vandewater et al., 2006). Further, previous meta-analytic estimates indicate negative associations between screen time and the quality of parent-child interactions (Kostyrka-Allchorne et al., 2017).

Preschool-aged children spent an average of $52 \mathrm{~h}$ per week across both types of hands-on play (i.e., combined hands-on play and total hands-on play), $17 \mathrm{~h}$ engaged in combined screen time, and $15 \mathrm{~h}$ in parent-supervised screen time. While school-aged children spent an average of $42 \mathrm{~h}$ per week across both types of hands-on play, $17 \mathrm{~h}$ doing combined screen time, and $18 \mathrm{~h}$ of parent-supervised screen time. While the current study did not have a longitudinal sample to assess changes over time, comparisons to published data would suggest significant changes to parent-child interactions. Results from a pre-pandemic normative sample found that American families reported spending $2.31 \mathrm{~h}$ per week in hands-on play (United States Bureau of Labor Statistics, 2019). Similarly, a Canadian normative sample found that families spent $2.5 \mathrm{~h}$ a week on childcare activities, including physical care, reading to, or talking with children (Statistics Canada, 2015). These statistics are substantially less than what families recruited during the pandemic reported in our survey. This result is likely a direct reflection of families spending more time at home and children spending less time at school/daycare. 
Our findings highlight the dramatic changes that parents and children experienced in family dynamics during the first three months of the COVID-19 pandemic. Pre-pandemic research from the American Academy of Pediatrics noted parents and children were spending diminished time in hands-on play (Ginsburg, 2007; Yogman et al., 2018). This further highlights the increased time spent in play in our sample. Similarly, prepandemic Canadian families reported supervising just over $13 \mathrm{~h}$ of screen time a week, compared to over $16 \mathrm{~h}$ in our sample (ParticipACTION, 2018). These increases may be in part due to families spending more time at home remote-learning and working (Bhamani et al., 2020).

Our study examined indicators of SES across childcare needs to better understand how various families were experiencing the effects of the pandemic. Although our study included a mostly high SES sample, indices of lower relative SES (e.g., parent education, household income, food insecurity) within the sample emerged across childcare needs and child age groups as significant factors associated with more time spent with children including hands-on play, combined screen time, and supervised screen time. In general, parents of lower SES may be more likely to have worked in exosystems that were directly impacted by the COVID-19 pandemic, such as hospitality or retail, allowing more time at home to be spent engaging in dyadic activities (Flemming, 2015; Gursoy \& Chi, 2020; Lemieux, 2020). More research is needed to better understand the needs of parents associated with spending more time at home engaging in parent-child interactions, regardless of SES.

Parents without childcare needs and lower parenting stress levels reported more time spent during hands-on play across child age groups. This finding follows the same trend as pre-pandemic research that identified a relationship between lower parenting stress and increased playful mother-child interactions (e.g., playing with toys or singing together; Zhang et al., 2019). In the screen time domain, parents without childcare needs experiencing higher levels of parenting stress reported more screen time for preschool-aged children. This finding is unsurprising, as parents are experiencing unique challenges during the pandemic and may be utilizing child screen time to cope with the pandemic. Although screens may be helpful to allow momentary parental relief, research indicates that early childhood screen habits are reflected in later screen use, which may represent a risk factor for anxiety and depression in youth (Maras et al., 2015; Xu et al., 2016). Further, higher screen use in childhood is predictive of lower academic performance and well-being (Hinkley et al., 2014; Mundy et al., 2020). Therefore, research investigating interventions to reduce parenting stress may be warranted to promote child well-being during and following the pandemic through supporting positive parent-child interactions.

For parents with unmet childcare needs, higher parental anxiety was associated with more time spent in hands-on play across child age groups. Such dyadic engagement may be a means through which parents are coping with anxiety, consistent with a distraction or pleasurable activity (Carver, 1997). However, there may be elements of play that are less supportive in the context of parental anxiety, such as reduced parental scaffolding, more over-controlling behaviours, and less warm or sensitive behaviours (Nicol-Harper et al., 2007; Schrock \&Woodruff-Border, 2010; Whaley et al., 1999). Of note, prior research is in non-pandemic samples, and we do not know the extent to which play quality is impacted by short-term pandemic-related anxiety versus more chronic anxiety. Therefore, more information is needed about the quality of hands-on interactions for parents with clinically elevated levels of anxiety during the pandemic.

In multi-adult families without childcare needs, the reporting parent indicated that they were able to spend more time in hands-on play with school-aged child(ren) compared to 
single-parent families. The number of children in the home was also associated with family activities. In families without childcare needs, parents of preschool-aged children indicated that having more children in the household was related to less hands-on play and more supervised screen time. Conversely, families with unmet childcare needs reported that having more children in the household was related to less total hands-on play and more combined hands-on play. In summary, families with more children reported less weekly handson play, but more family-based play activities (e.g., dance or music activities, making meals or snacks together, arts and crafts, and playing with toys together). It was also noted that non-mothers (i.e., fathers or participants who described themselves simply as a "parent") reported engaging in more hands-on play, compared to mothers. However, this finding is preliminary due to the small sample size of non-mothers in our study. It is possible that shifts in exosystems, such as family roles and routines due to the pandemic (e.g., working from home), may in part explain the reported involvement of fathers in more childcare (Alon, Doepke, Olmstead-Rumsey, \& Tertilt, 2020). Further, men's employment is often in sectors that are more affected by recessions, such as manufacturing and trades, compared to sectors such as education and health care where women are more likely to work (Alon et al., 2020). As such, fathers' work may have been more likely to be impacted through layoffs and furloughs, resulting in greater time spent at home.

\section{Intervention Considerations}

Given our findings, there are three main avenues through which support may be provided to families with young children during the pandemic. First, exposure to parents experiencing mental health challenges, such as anxiety, can have detrimental effects on young children's well-being (Bauer et al., 2013; Shonkoff \& Fisher, 2013). Yet, research indicates that children's well-being is fostered when parent mental health is supported with intervention, limiting the intergenerational health risk to children (Fredriksen et al., 2019; Thanhäuser et al., 2017). As such, it is crucial that parental mental health needs are identified and timely services are provided. For instance, cognitive-behavioural therapy is one such intervention that has a well-established evidence-base for treating anxiety (Carpenter et al., 2018; Hofmann \& Smits, 2008; Ekers et al., 2008). Further, research indicates that parenting stress is directly related to responsive parenting, which in turn influences child cognitive development and prosocial child behaviours (Ward \& Lee, 2020). Therefore, evidence-based programs aiming to reduce parenting stress, including parenting programs such as 1-2-3 Magic, should be made widely available during this time (Bloomfield \& Kendall, 2012). Under situations like the COVID-19 pandemic, additional considerations regarding parent capacity to access mental health services and parenting programs are necessary, given the increased demands on parenting. One example is mental health services that are offered via videoconference. Telehealth services reduce some barriers presented by in-person sessions, such as navigating challenges related to daycare/school closures. Parent-specific considerations are important during and following the pandemic to best support families in need.

Further, interventions aimed at increasing high-quality and positive parent-child interactions specifically should be reviewed and broadly implemented during the pandemic for families in need. Evidenced-based and widely disseminated parenting interventions for consideration are Parent-Child Interaction Therapy and Triple P-Positive Parenting Program. These programs have positive effects on reducing parent-related stress, difficult child behaviours, and increasing positive parenting strategies (Thomas \& Zimmer-Gembeck, 2007; Thomas et al., 2017). While the effectiveness of these interventions on reducing 
external COVID-19-related stressors is unknown, they have the potential to mitigate mechanisms impeding parent-child functioning during the pandemic.

The recommendations from the American Academy of Pediatrics (2018) to minimize media consumption for young children were difficult for many families to achieve prepandemic (Atkin et al., 2014). Within the context of the COVID-19 pandemic, screen use has likely increased as a function of shifting social connection and online learning. From a developmental perspective, engaging in these activities through screens, as opposed to not at all, is likely preferable (Skora Horgan \& Poehlmann-Tynan, 2020). While reductions in screen time may be warranted in some cases, it is necessary to recognize the utility of screen time for families seeking relief and restoration from stressors during the pandemic. Supporting parents in choosing high-quality media such as educational apps that are evidence-based to support learning should be considered (Hirsh-Pasek, 2015). More broadly, the strategic use of screen time for social activities, such as videoconferencing with family and friends, should be encouraged when families are not physically able to be together given the significant benefits of social connection (McClure \& Barr, 2017). Little is known about the extent to which screen use during the pandemic will be linked to developmental outcomes for children of any age. Future research should closely evaluate child screen use prospectively to allow for the early identification of problematic use related to the pandemic.

\section{Strengths and Limitations}

Limitations include cross-sectional data, which impacted the ability to explore causal relationships and provide insight into pre- and post-pandemic functioning. A further methodological limitation of the study was the use of self-report questionnaires. Parents reported all information, including the types of activities they engaged in with their child(ren). Therefore, the quality of these activities was not objectively observed by the researchers. An additional limitation of the study was that the study questionnaires did not ask about parents' change in childcare needs as a direct result of the pandemic; instead, childcare need was based on cross-sectional need at the time of assessment. Similarly, information about parental work type (e.g., working from home or working out of the home) and specific changes to the home environment during the COVID-19 pandemic were not collected. Instead, variables such as parental employment loss were used as indicators of change at home. The sample had minimal diversity as it included a high proportion of mothers, White parents, and individuals of higher SES. Therefore, generalizability to racial or ethnic minority and low SES populations should be treated with caution. This is particularly important given the differential impact of the pandemic on these populations. Yet, the online means of the current study allowed for the large sample size to be collected over a relatively short amount of time during a global shutdown. Nevertheless, the study provides a snapshot into parent and family factors linked to family activities during the pandemic at a time when school and daycare closures were in effect.

Despite these limitations, the study provides insight into how a large sample of 708 parents, including both mothers and fathers, managed parenting demands and parent-child interactions during the COVID-19 pandemic. The study was completed under an expedited timeline to capture important information to inform supports and programs needed for parents and their young children. As a result, this study provides important and novel insight into the functioning of families during the pandemic, along with a foundation for future research and intervention considerations as the pandemic unfolds. 


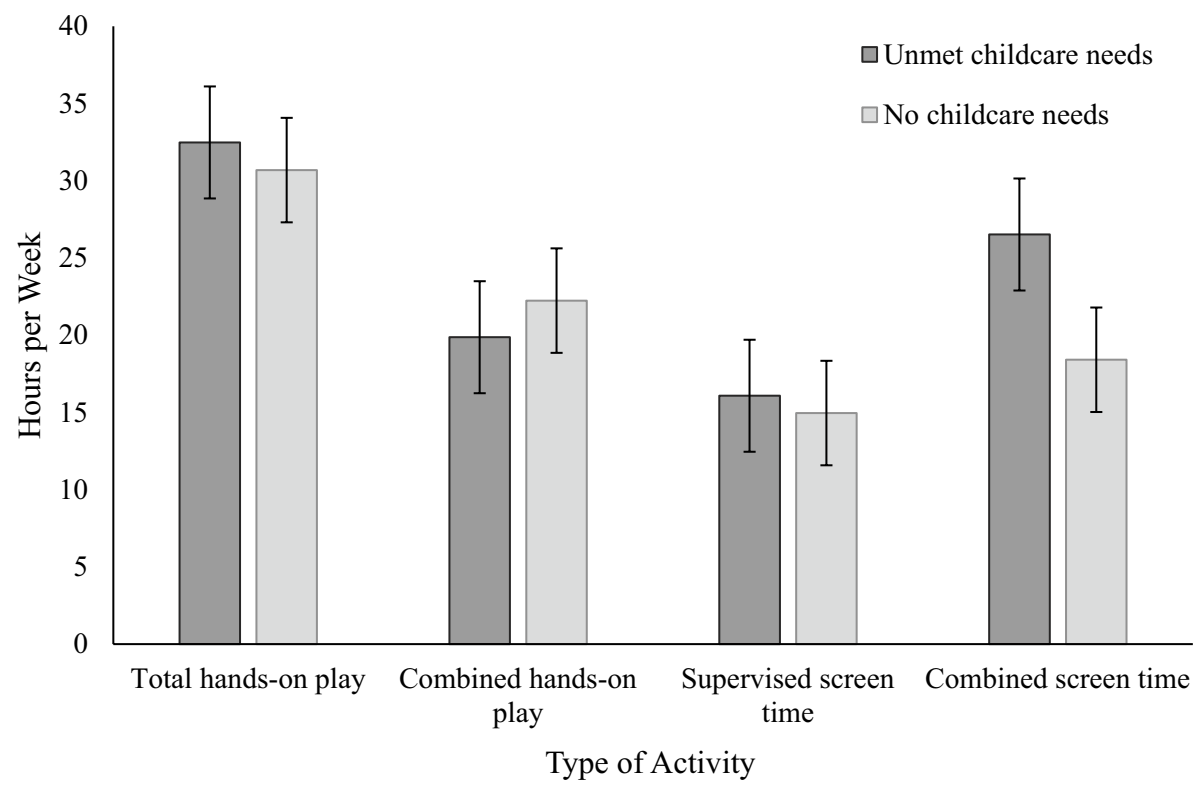

Fig. 1 Parent-Child Interaction Time with Standard Error Bars for Parents of Children Age 2 to 4 Years Old with Respect to Childcare Needs

\section{Future Directions}

Future research should continue to evaluate family functioning in the context of changing external COVID-19-related factors and pressures. Examining screen use and hands-on play across a more diverse global sample and developmental stages would further inform the nature of parent-child activities in different family contexts. Additionally, future research should consider investigating if supervised screen time in families is due to increased time children are spending with screens or if it reflects increased awareness by parents of screen time use due to being home during the pandemic. It would also be beneficial to conduct a follow-up study to investigate the evolving family activities used and resources needed as the COVID-19 landscape rapidly changes over the coming months.

\section{Conclusions}

Worldwide, families have experienced the effects of the COVID-19 pandemic on various scales. The current study highlights the family factors associated with screen use and handon parent-child activities, which are expected to have different developmentally supportive implications for young children. To promote high-quality parent-child interactions and positive child development, future research efforts and interventions should support families across parental mental health, parenting stress, family demographic factors, and childcare needs. Further, additional research about the relative value of different types of screen use is needed to guide media usage during a time where the world is generally more reliant 


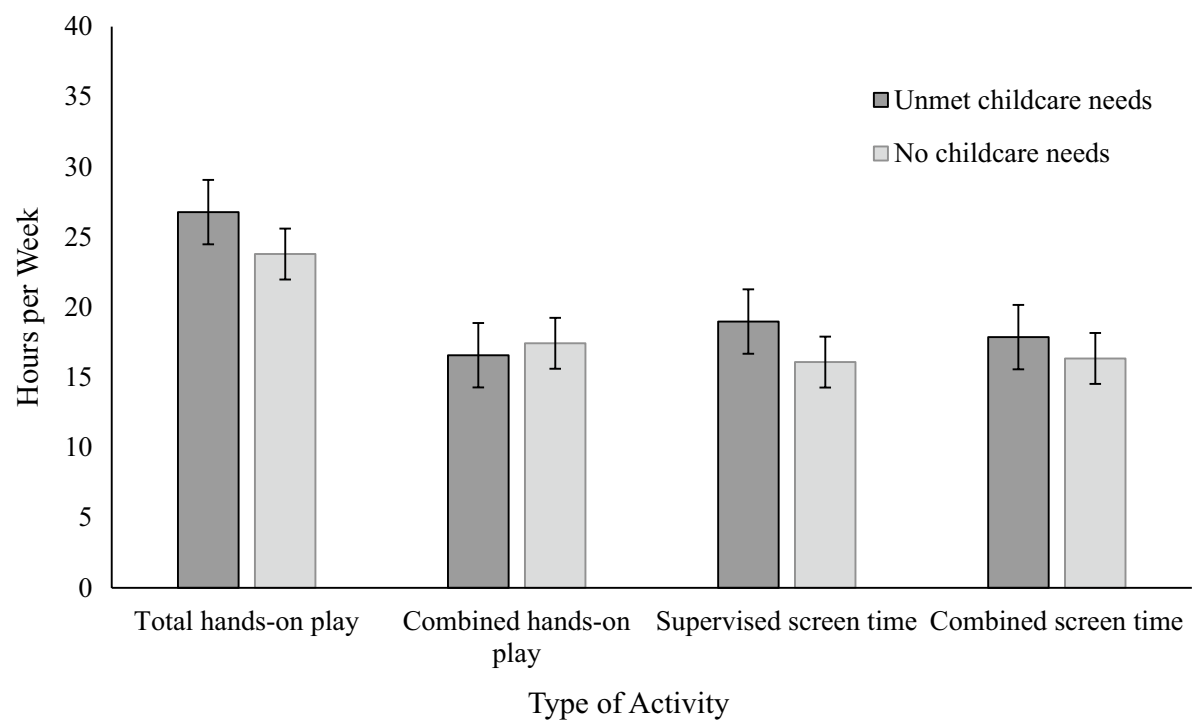

Fig. 2 Parent-Child Interaction Time with Standard Error Bars for Parents of Children Age 5 to 8 Years Old with Respect to Childcare Needs

on technology. In doing so, positive developmental outcomes may be encouraged despite the many changing pressures on pre-pandemic developmental supports (Figs. 1, 2).

\section{References}

Abidin, R. R. (2012). Parenting stress index (4th ed.). PAR.

Alon, T. M., Doepke, M., Olmstead-Rumsey, J., \& Tertilt, M. (2020). The impact of COVID-19 on gender equality (No. w26947). National Bureau of Economic Research.

American Academy of Pediatrics. Children and media tips from the American Academy of Pediatrics. https://www.aap.org/en-us/about-the-aap/aap-press-room/news-features-and-safety-tips/Pages/Child ren-and-Media-Tips.aspx Published May 1, 2018. Accessed May 28, 2020.

Atkin, A. J., Sharp, S. J., Corder, K., van Sluijs, E. M., \& International Children's Accelerometry Database (ICAD) Collaborators. (2014). Prevalence and correlates of screen time in youth: an international perspective. American Journal of Preventive Medicine, 47(6), 803-807https://doi.org/10.1016/j.amepre. 2014.07.043

Barnett, M. A., Gustafsson, H., Deng, M., Mills-Koonce, W. R., \& Cox, M. (2012). Bidirectional associations among sensitive parenting, language development, and social competence. Infant and Child Development, 21(4), 374-393. https://doi.org/10.1002/icd.1750

Bauer, N. S., Gilbert, A. L., Carroll, A. E., \& Downs, S. M. (2013). Associations of early exposure to intimate partner violence and parental depression with subsequent mental health outcomes. JAMA Pediatrics, 167(4), 341-347. https://doi.org/10.1001/jamapediatrics.2013.780

Bhamani, S., Makhdoom, A. Z., Bharuchi, V., Ali, N., Kaleem, S., \& Ahmed, D. (2020). Home learning in times of COVID: Experiences of Parents. Journal of Education andEducational Development, 7(1), 9-26. https://doi.org/10.22555/joeed.v7i1.3260

Bloomfield, L., \& Kendall, S. (2012). Parenting self-efficacy, parenting stress and child behaviour before and after a parenting programme. Primary Health Care Research \& Development, 13(4), 364-372. https://doi.org/10.1017/S1463423612000060

Bronfenbrenner, U. (1986). Ecology of the family as a context for human development: Research perspectives. Developmental Psychology, 22(6), 723-742.

Brown, S. M., Doom, J. R., Lechuga-Peña, S., Watamura, S. E., \& Koppels, T. (2020). Stress and parenting during the global COVID-19 pandemic. Child Abuse \& Neglect, 110, 104699. 
Cameron, E. E., Joyce, K., Delaquis, C., Reynolds, K., Protudjer, J., \& Roos, L. E. (2020, May 2). Maternal Psychological Distress \& Mental Health Service Use during the COVID-19 Pandemic. https://doi.org/ 10.31234/osf.io/a53zb

Carpenter, J. K., Andrews, L. A., Witcraft, S. M., Powers, M. B., Smits, J. A., \& Hofmann, S. G. (2018). Cognitive behavioral therapy for anxiety and related disorders: A meta-analysis of randomized placebo-controlled trials. Depression and Anxiety, 35(6), 502-514. https://doi.org/10.1002/da.22728

Carver, C. S. (1997). You want to measure coping but your protocol's too long: Consider the brief cope. International Journal of Behavioral Medicine, 4(1), 92-100.

Cluver, L., Lachman, J. M., Sherr, L., Wessels, I., Krug, E., Rakotomalala, S., \& McDonald, K. (2020). Parenting in a time of COVID-19. The Lancet, 395(10231), E64. https://doi.org/10.1016/S0140-6736(20) 30736-4

Conger, R. D., Ge, X., Elder, G. H., Jr., Lorenz, F. O., \& Simons, R. L. (1994). Economic stress, coercive family process, and developmental problems of adolescents. Child Development, 65(2), 541-561.

Conger, R. D., \& Donnellan, M. B. (2007). An interactionist perspective on the socioeconomic context of human development. Annual Review of Psychology, 58, 175-199. https://doi.org/10.1146/annurev. psych.58.110405.085551

Cote, L. R., \& Bornstein, M. H. (2009). Child and mother play in three US cultural groups: Comparisons and associations. Journal of Family Psychology, 23(3), 355. https://doi.org/10.1037/a0015399

Domingues-Montanari, S. (2017). Child and psychological benefits of excessive screen time on children. Journal of Paediatrics and Child Health., 53(4), 333-338. https://doi.org/10.1111/jpc.13462

Dubois-Comtois, K., Moss, E., Cyr, C., \& Pascuzzo, K. (2013). Behavior problems in middle childhood: The predictive role of maternal distress, child attachment, and mother-child interactions. Journal of Abnormal Child Psychology, 41(8), 1311-1324.

Duch, H., Fisher, E. M., Ensari, I., \& Harrington, A. (2013). Screen time use in children under 3 years old: a systematic review of correlates. International Journal of Behavioral Nutrition and Physical Activity, 10(1), 102. https://doi.org/10.1186/1479-5868-10-102

Eaton, W., Smith, C., Ybarra, M., Muntaner, C., \& Tien, A. (2004). Center for Epidemiologic Studies Depression Scale: Review and Revision (CESD and CESD-R). In M. E. Maruish (Ed.), The use of psychological testing for treatment planning and outcomes assessment: Instruments for adults (pp. 363-377). Lawrence Erlbaum Associates Publishers.

Edhborg, M., Lundh, W., Seimyr, L., \& Widström, A. M. (2003). The parent-child relationship in the context of maternal depressive mood. Archives of Women's Mental Health, 6(3), 211-216. https://doi.org/ 10.1007/s00737-003-0020-x

Ekers, D., Richards, D., \& Gilbody, S. (2008). A meta analysis of randomised trials of behavioural treatment of depression. Psychological Medicine., 38(5), 611-623. https://doi.org/10.1017/S0033291707001614

Elias, N., \& Sulkin, I. (2019). Screen-assisted parenting: The relationship between toddlers' screen time and parents' use of media as a parenting tool. Journal of Family Issues, 40(18), 2801-2822.

Evans, G. W., \& Kim, P. (2013). Childhood poverty, chronic stress, self-regulation, and coping. Child Development Perspectives, 7(1), 43-48. https://doi.org/10.1111/cdep.12013

Eyimaya, A. O., \& Irmak, A. Y. (2021). Relationship between parenting practices and children's screen time during the COVID-19 Pandemic in Turkey. Journal of Pediatric Nursing, 56, 24-29.

Fay-Stammbach, T., Hawes, D. J., \& Meredith, P. (2014). Parenting influences on executive function in early childhood: A review. Child Development Perspectives, 8(4), 258-264. https://doi.org/10.1111/ cdep. 12095

Field, T. (2018). Paternal Prenatal, Perinatal and Postpartum Depression: A narrative review. Journal of Anxiety \& Depression, 1(1), 1-16.

Fredriksen, E., von Soest, T., Smith, L., \& Moe, V. (2019). Parenting stress plays a mediating role in the prediction of early child development from both parents' perinatal depressive symptoms. Journal of Abnormal Child Psychology, 47(1), 149-164. https://doi.org/10.1007/s10802-018-0428-4

Gardner, F. E. (1994). The quality of joint activity between mothers and their children with behaviour problems. Journal of Child Psychology and Psychiatry, 35(5), 935-948. https://doi.org/10.1111/j.14697610.1994.tb02303.x

Gardner, F. (2000). Methodological issues in the direct observation of parent-child interaction: Do observational findings reflect the natural behavior of participants? Clinical Child and Family Psychology Review, 3, 185-198.

Gardner, F., Ward, S., Burton, J., \& Wilson, C. (2003). The role of mother-child joint play in the early development of children's conduct problems: A longitudinal observational study. Social Development, 12(3), 361-378. https://doi.org/10.1111/1467-9507.00238

Gaudreau, C., King, Y. A., Dore, R. A., Puttre, H., Nichols, D., Hirsh-Pasek, K., \& Golinkoff, R. M. (2020). Preschoolers benefit equally from video chat, pseudo-contingent video, and live book reading: 
Implications for storytime during the Coronavirus pandemic and beyond. Frontiers in Psychology, 11, 1-17. https://doi.org/10.3389/fpsyg.2020.02158

Ginsburg, K. R. (2007). The importance of play in promoting healthy child development and maintaining strong parent-child bonds. Pediatrics, 119(1), 182-191. https://doi.org/10.1542/peds.2006-2697

Goodman, S. H., Rouse, M. H., Connell, A. M., Broth, M. R., Hall, C. M., \& Heyward, D. (2011). Maternal depression and child psychopathology: A meta-analytic review. Clinical Child and Family Psychology Review, 14(1), 1-27. https://doi.org/10.1007/s10567-010-0080-1

Gursoy, D., \& Chi, C. G. (2020). Effects of COVID-19 pandemic on hospitality industry: review of the current situations and a research agenda. Journal of Hospitality Marketing \& Management, 29(5), 527529. https://doi.org/10.1080/19368623.2020.1788231

Harris, P. A., Taylor, R., Thielke, R., Payne, J., Gonzalez, N., \& Conde, J. G. (2009). Research electronic data capture (REDCap) - A metadata-driven methodology and workflow process for providing translational research informatics support. Journal of Biomedical Informatics, 42(2), 377-381. https://doi. org/10.1016/j.jbi.2008.08.010

Hinkley, T., Teychenne, M., Downing, K. L., Ball, K., Salmon, J., \& Hesketh, K. D. (2014). Early childhood physical activity, sedentary behaviors and psychosocial well-being: A systematic review. Preventive Medicine, 62, 182-192. https://doi.org/10.1016/j.ypmed.2014.02.007

Hirsh-Pasek, K., Zosh, J. M., Golinkoff, R. M., Gray, J. H., Robb, M. B., \& Kaufman, J. (2015). Putting education in "educational" apps: Lessons from the science of learning. Psychological Science in the Public Interest, 16(1), 3-34.

Hoffman, L. W. (2003). Methodological issues in studies of SES, parenting, and child development. Socioeconomic Status, Parenting, and Child Development, 125-143.

Hoffmann, J., \& Russ, S. (2012). Pretend play, creativity, and emotion regulation in children. Psychology of Aesthetics, Creativity, and the Arts, 6(2), 175-184. https://doi.org/10.1037/a0026299

Hofmann, S. G., \& Smits, J. A. (2008). Cognitive-behavioral therapy for adult anxiety disorders: A metaanalysis of randomized placebo-controlled trials. The Journal of Clinical Psychiatry, 69(4), 621-632.

Kostyrka-Allchorne, K., Cooper, N. R., \& Simpson, A. (2017). The relationship between television exposure and children's cognition and behaviour: A systematic review. Developmental Review, 44, 19-58.

Lauricella, A. R., Wartella, E., \& Rideout, V. J. (2015). Young children's screen time: The complex role of parent and child factors. Journal of Applied Developmental Psychology, 36, 11-17. https://doi.org/10. 1016/j.appdev.2014.12.001

Lemieux, T., Milligan, K., Schirle, T., \& Skuterud, M. (2020). Initial impacts of the COVID-19 pandemic on the Canadian labour market. Canadian Public Policy, 46(S1), S55-S56. https://doi.org/10.3138/ cpp.2020-049

Linsey, E. W., \& Colwell, M. J. (2003). Preschoolers' emotional competence: Links to pretend and physical play. Child Study Journal, 33(1), 39-53.

Loades, M. E., Chatburn, E., Higson-Sweeney, N., Reynolds, S., Shafran, R., Brigden, A., \& Crawley, E. (2020). Rapid Systematic Review: The Impact of Social Isolation and Loneliness on the Mental Health of Children and Adolescents in the Context of COVID-19. Journal of the American Academy of Child \& Adolescent Psychiatry.

MacDonald, D. (2018). Childcare deserts in Canada. Retrieved from https://www.policyalternatives.ca/sites/ default/files/uploads/publications/National\%20Office/2018/06/Child\%20Care\%20Deserts.pdf.

Madigan, S., McArthur, B. A., Anhorn, C., Eirich, R., \& Christakis, D. A. (2020). Associations Between Screen Use and Child Language Skills: A Systematic Review and Meta-analysis. JAMA Pediatrics. https://doi.org/10.1001/jamapediatrics.2020.0327

Malik, R. \& Hamm, K. (2017). Mapping America's child care deserts. Retrieved from https://www.ameri canprogress.org/issues/early-childhood/reports/2017/08/30/437988/mappingamericas-child-care-deser ts/.

Maras, D., Flament, M. F., Murray, M., Buchholz, A., Henderson, K. A., Obeid, N., \& Goldfield, G. S. (2015). Screen time is associated with depression and anxiety in Canadian youth. Preventive Medicine, 73, 133-138.

McArthur, B. A., Tough, S., \& Madigan, S. (2021). Screen time and developmental and behavioral outcomes for preschool children. Pediatric Research, 1-6.

McClure, E., \& Barr, R. (2017). Building family relationships from a distance: Supporting connections with babies and toddlers using video and video chat. In Media exposure during infancy and early childhood (pp. 227-248). Springer, Cham.

McDonald, S., Kehler, H., Bayrampour, H., Fraser-Lee, N., \& Tough, S. (2016). Risk and protective factors in early child development: Results from the All Our Babies (AOB) pregnancy cohort. Research in Developmental Disabilities, 58, 20-30. https://doi.org/10.1016/j.ridd.2016.08.010 
McMillin, S. E., Hall, L., Bultas, M. W., Grafeman, S. E., Wilmott, J., Maxim, R., \& Zand, D. H. (2015). Knowledge of child development as a predictor of mother-child play interactions. Clinical pediatrics, 54(11), 1117-1119.

Menashe-Grinberg, A., \& Atzaba-Poria, N. (2017). Mother-child and father-child play interaction: The importance of parental playfulness as a moderator of the links between parental behavior and child negativity. Infant mental health journal, 38(6), 772-784. https://doi.org/10.1002/imhj.21678

Morris, A. S., Silk, J. S., Steinberg, L., Myers, S. S., \& Robinson, L. R. (2007). The role of the family context in the development of emotion regulation. Social Development, 16(2), 361-388. https://doi. org/10.1111/j.1467-9507.2007.00389.x

Mundy, L. K., Canterford, L., Hoq, M., Olds, T., Moreno-Betancur, M., Sawyer, S., \& Patton, G. C. (2020). Electronic media use and academic performance in late childhood: A longitudinal study. PLoS ONE, 15(9), e0237908. https://doi.org/10.1371/journal.pone.0237908

Nicol-Harper, R., Harvey, A. G., \& Stein, A. (2007). Interactions between mothers and infants: Impact of maternal anxiety. Infant Behavior and Development, 30(1), 161-167. https://doi.org/10.1016/j. infbeh.2006.08.005

Neumann, M. M. (2018). Using tablets and apps to enhance emergent literacy skills in young children. Early Childhood Research Quarterly, 42, 239-246. https://doi.org/10.1016/j.ecresq.2017.10. 006

Pagani, L. S., Fitzpatrick, C., \& Barnett, T. A. (2013). Early childhood television viewing and kindergarten entry readiness. Pediatric Research, 74(3), 350-355. https://doi.org/10.1038/pr.2013.105

ParticipACTION. (2018). Canadian kids need to move more to boost their health: The ParticipACTION report card on physical activity for children and youth. Retrieved from https://participaction.cdn. prismic.io/participaction\%2F38570bed-b325-4fc8-8855-f15c9aebac12_2018_participaction_ report_card_-_full_report_0.pdf

Poulain, T., Vogel, M., Neef, M., Abicht, F., Hilbert, A., Genuneit, J., \& Kiess, W. (2018). Reciprocal associations between electronic media use and behavioral difficulties in preschoolers. International Journal of Environmental Research and Public Health, 15(4), 814. https://doi.org/10.3390/ijerph15040814

Priel, A., Djalovski, A., Zagoory-Sharon, O., \& Feldman, R. (2019). Maternal depression impacts child psychopathology across the first decade of life: Oxytocin and synchrony as markers of resilience. Journal of Child Psychology and Psychiatry, 60(1), 30-42. https://doi.org/10.1111/jcpp.12880

Radesky, J. S., Silverstein, M., Zuckerman, B., \& Christakis, D. A. (2014). Infant self-regulation and early childhood media exposure. Pediatrics, 133(5), e1172-e1178. https://doi.org/10.1542/peds.2013-2367

Radesky, J. S., \& Christakis, D. A. (2016). Increased screen time: Implications for early childhood development and behavior. Pediatric Clinics, 63(5), 827-839. https://doi.org/10.1016/j.pcl.2016.06.006

Radloff, L. S. (1977). The CES-D Scale. Applied Psychological Measurements, 1(3), 385-401.

Roos, L. E., Salisbury, M., Penner-Goeke, L., Cameron, E. E., Protudjer, J. L., Giuliano, R., Afifi, T. O., \& Reynolds, K. (2021). Supporting families to protect child health: Parenting quality and household needs during the COVID-19 pandemic. Plos one, 16(5), e0251720.

Rosa, E. M., \& Tudge, J. (2013). Urie Bronfenbrenner's theory of human development: Its evolution from ecology to bioecology. Journal of Family Theory \& Review, 5(4), 243-258. https://doi.org/10. $1111 /$ jftr. 12022

Rowe, M. L. (2012). A longitudinal investigation of the role of quantity and quality of child-directed speech in vocabulary development. Child Development, 83(5), 1762-1774. https://doi.org/10. 1111/j.1467-8624.2012.01805.x

Sanchez-Villegas, A., Schlatter, J., Ortuno, F., Lahortiga, F., Pla, J., Benito, S., \& Martinez- Gonzalez, M. A. (2008). Validity of a self-reported diagnosis of depression among participants in a cohort study using the Structured Clinical Interview for DSM-IV (SCID-I). BMC Psychiatry, 8(1), 43. https://doi.org/10.1186/1471-244X-8-43

Schrock, M., \& Woodruff-Borden, J. (2010). Parent-child interactions in anxious families. Child \& Family Behavior Therapy, 32(4), 291-310. https://doi-org.uml.idm.oclc.org/https://doi.org/10.1080/ 07317107.2010 .515523

Shaffer, A., \& Obradović, J. (2017). Unique contributions of emotion regulation and executive functions in predicting the quality of parent-child interaction behaviors. Journal of Family Psychology, 31(2), 150. https://doi.org/10.1037/fam0000269

Shin, H.D., \& Al-Habaibeh, A. (2020, June 3). Coronavirus: how to reduce your children's screen time - and make them more active. The Conversation. https://theconversation.com/coronavirus-how-toreduce-your-childrens-screen-time-and-make-them-more-active-136549

Shonkoff, J. P., \& Fisher, P. A. (2013). Rethinking evidence-based practice and two-generationprograms to create the future of early childhood policy. Development and psychopathology, 25(4 0 2), 1635. https://doi.org/10.1017/S0954579413000813 
Shonkoff, J. P., Richmond, J., Levitt, P., Bunge, S. A., Cameron, J. L., Duncan, G. J., \& Nelson, C. A., III. (2016). From best practices to breakthrough impacts a science-based approach to building a more promising future for young children and families. Harvard University, Center on the Developing Child.

Skora Horgan, E., \& Poehlmann-Tynan, J. (2020). In-home video chat for young children and their incarcerated parents. Journal of Children and Media, 14(3), 400-406.

Spitzer, R. L., Kroenke, K., Williams, J. B. W., \& Löwe, B. (2006). A brief measure for assessing generalized anxiety disorder: The GAD-7. Archives of Internal Medicine, 166(10), 1092-1097. https://doi.org/ 10.1001/archinte.166.10.1092

Statistics Canada Labour Force Survey. (2020, June 5). COVID-19 and the labour market in May 2020. from https://www150.statcan.gc.ca/n1/pub/11-627-m/11-627-m2020038-eng.htm

Statistics Canada. (2015, November 30). General social survey - 2010 overview of the time use of Canadians. https://www150.statcan.gc.ca/n1/pub/89-647-x/2011001/hl-fs-eng.htm

Sweeney, S., \& MacBeth, A. (2016). The effects of paternal depression on child and adolescent outcomes: A systematic review. Journal of Affective Disorders, 205, 44-59. https://doi.org/10.1016/j.jad.2016.05. 073

Thanhäuser, M., Lemmer, G., de Girolamo, G., \& Christiansen, H. (2017). Do preventive interventions for children of mentally ill parents work? Results of a systematic review and meta-analysis. Current Opinion in Psychiatry, 30(4), 283-299.

Thomas, R., \& Zimmer-Gembeck, M. J. (2007). Behavioral outcomes of parent-child interaction therapy and Triple P-Positive Parenting Program: A review and meta-analysis. Journal of Abnormal Child Psychology, 35(3), 475-495. https://doi.org/10.1007/s10802-007-9104-9

Thomas, R., Abell, B., Webb, H. J., Avdagic, E., \& Zimmer-Gembeck, M. J. (2017). Parent-child interaction therapy: a meta-analysis. Pediatrics, 140(3), e20170352. https://doi-org.uml.idm.oclc.org/https://doi. org/10.1542/peds.2017-0352

United States Bureau of Labor Statistics. (2019). Average hours per day parents spent caring for and helping household children as their main activity. https://www.bls.gov/charts/american-time-use/activityby-parent.htm

Van Gampelaere, C., Luyckx, K., Goethals, E. R., van der Straaten, S., Laridaen, J., \& Casteels, K., \& Goubert, L. (2020). Parental stress, anxiety and trait mindfulness: Associations with parent-child mealtime interactions in children with type 1 diabetes. Journal of Behavioral Medicine. https://doi.org/10.1007/ s10865-020-00144-3

Vandewater, E. A., Bickham, D. S., \& Lee, J. H. (2006). Time well spent? Relating television use to children's free-time activities. Pediatrics, 117(2), e181-e191.

Ward, K. P., \& Lee, S. J. (2020). Mothers' and fathers' parenting stress, responsiveness, and child wellbeing among low-income families. Children and Youth Services Review, 116, 105218. https://doi.org/10. 1016/j.childyouth.2020.105218

Wilson, S., \& Durbin, C. E. (2010). Effects of paternal depression on fathers' parenting behaviors: A metaanalytic review. Clinical Psychology Review, 30(2), 167-180. https://doi.org/10.1016/j.cpr.2009.10. 007

Whaley, S. E., Pinto, A., \& Sigman, M. (1999). Characterizing interactions between anxious mothers and their children. Journal of Consulting and Clinical Psychology, 67(6), 826. https://doi.org/10.1037/ 0022-006X.67.6.826

Xu, H., Wen, L. M., Hardy, L. L., \& Rissel, C. (2016). A 5-year longitudinal analysis of modifiable predictors for outdoor play and screen-time of 2-to 5-year-olds. International Journal of Behavioral Nutrition and Physical Activity, 13(1), 96. https://doi.org/10.1186/s12966-016-0422-6

Yogman, M., Garner, A., Hutchinson, J., Hirsh-Pasek, K., Golinkoff, R. M., \& Committee on Psychosocial Aspects of Child and Family Health. (2018). The power of play: A pediatric role in enhancing development in young children. Pediatrics, 142(3). https://doi.org/10.1542/peds.2018-2058

Zhang, C., Cubbin, C., \& Ci, Q. (2019). Parenting stress and mother-child playful interaction: The role of emotional support. Journal of Family Studies, 25(2), 101-115. https://doi.org/10.1080/13229400.2016. 1200113

Publisher's Note Springer Nature remains neutral with regard to jurisdictional claims in published maps and institutional affiliations. 